\title{
Carreira e salário do pessoal docente da Educação Básica: algumas demarcações legais ${ }^{1}$
}

\author{
Rubens Barbosa de Camargo ${ }^{2}$ \\ rubensbc@usp.br \\ Márcia Aparecida Jacomini ${ }^{3}$ \\ marciajacomini@uol.com.br
}

\begin{abstract}
Resumo:
No presente texto apresentam-se aspectos sobre carreira e salário do pessoal docente da Educação Básica em alguns documentos internacionais e na legislação brasileira, com foco nas Constituições Federais e leis infraconstitucionais. Verifica-se que orientações legais sobre carreira e salário do professor estão presentes na legislação nacional e em documentos internacionais há bastante tempo, denotando certa compreensão sobre a importância do professor no oferecimento de uma educação de qualidade. No entanto, não
\end{abstract}

\footnotetext{
1 Este artigo é parte da pesquisa nacional "Remuneração de professores de escolas públicas da educação básica: configurações, impactos, impasses e perspectivas", financiada segundo o Edital $n^{o}$. 001/2008 da CAPES / INEP / SECAD - Observatório da Educação, realizada junto ao Centro de Estudos e Pesquisas em Políticas Públicas de Educação (CEPPPE) da Faculdade de Educação da Universidade de São Paulo e coordenada nacionalmente pelo Prof. Dr. Rubens Barbosa de Camargo. Tal pesquisa está sendo desenvolvida em doze estados: São Paulo, Paraná, Rio Grande do Sul, Santa Catarina, Mato Grosso do Sul, Mato Grosso, Paraíba, Piauí, Roraima, Pará, Minas Gerais e Rio Grande do Norte, envolvendo nove programas de Pós-Graduação em Educação, quais sejam os da USP, UFPA, UFPI, UFPB, UFRN, UEMG, UFMS, UFPR, UNISUL e contando, ainda, com quatro grupos colaboradores de pesquisa: USP-RP, UNIFESP, UFMT, UFRGS. 2 FEUSP

3 UNIFESP - Diadema

4 Embora a responsabilidade pelo artigo seja dos autores, ele contou com contribuições da equipe de pesquisadores de São Paulo: Profa. Dra. Lisete Regina Gomes Arelaro (USP), Profa. Dra. Maria Angélica Pedra Minhoto (UNIFESP), Ms. Adriana Inácio Yanaguita (DoutoradoUNESP/Marília), Ana Paula Santiago do Nascimento (Mestrado - USP), Flávio Pinto Silva (IC-USP, até outubro/2010), Nilson de Souza (Mestrado - USP), Kátia Aparecida Santos (Auxiliar de Pesquisa - Profa. Rede Municipal/SP), Renata Rodrigues de Amorim Medina (IC-USP, desde julho/2010) e Cláudia Alves Pereira (Auxiliar de Pesquisa - Professora Rede Estadual/SP, após outubro/2010).
}

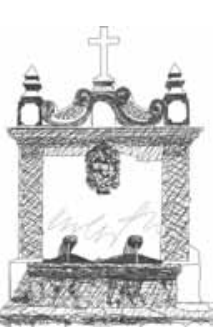


se pode falar de continuidade acerca das propostas, pois se percebem movimentos contraditórios em relação à garantia e aos avanços de direitos e à construção de uma carreira e de um salário condigno à condição docente. No Brasil, observa-se que maior preocupação com a carreira e o salário docentes, prescritos na legislação, ocorreu em períodos democráticos, tal como acontece com a vinculação constitucional relativa ao financiamento da educação. A partir da Constituição Federal de 1988, observa-se uma intensificação de legislações sobre carreira e salário de professores, com o estabelecimento do dever de estados e municípios elaborarem planos de cargo, carreira e salários para os profissionais da educação básica.

Palavras-chave: educação básica; salário de professor; carreira docente.

\section{Introdução}

Neste texto, pretende-se expor e analisar alguns aspectos legais, entendidos como importantes demarcações para as discussões sobre os planos de carreira e de salários do pessoal docente da educação básica ${ }^{5}$ e que são evidenciados a partir da segunda metade do século XX.

Tais discussões, é preciso salientar, ocorreram no marco da ampliação do acesso à escola e do debate sobre qualidade do ensino, tanto em termos nacionais quanto internacionais.

Nesse sentido, constata-se tanto a ampliação física das redes públicas (e privadas) de ensino quanto o aumento dos quadros necessários para tal atendimento. Concomitantemente, há uma expansão das tensões relativas às questões salariais, às condições de trabalho, às propostas pedagógicas, entre outras. Tais conflitos, que se apresentam inicialmente como fruto da manifestação organizada de reivindicações por meio de movimentos e ações

5 Para efeito deste artigo, embora se façam menções a diferentes documentos internacionais, entende-se o conceito de Educação Básica como aquele que envolve a Educação Infantil, o Ensino Fundamental e o Ensino Médio.

Ano 14 - n. 17 - julho 2011 - p. 129-167 
sindicais (ou mais amplas), se expressam também em diferentes configurações administrativo-políticas, na forma de leis, regulamentos, estatutos, decretos etc. A legislação neste texto é entendida como expressão da síntese dos projetos e interesses em disputa e da correlação de forças existente em cada momento histórico, ou seja, a documentação legal, de forma específica, expressa os conflitos engendrados pelos interesses diferenciados entre quem trabalha na escola (em geral, o agente da ação docente) e os empresariais ou governamentais. Infelizmente, aqui não se tratará da dinâmica que envolve os fatores e os agentes em disputa.

O texto se apresenta em três partes: a primeira destaca documentos e discussões internacionais a respeito da temática; a segunda demarca a presença da mesma nas Constituições Brasileiras e legislação infraconstitucional antes da Constituição Federal de 1988 (CF/88); a terceira evidencia aspectos sobre os planos de carreira e salários do pessoal docente no período pós $\mathrm{CF} / 88$.

\section{1- Documentos e discussões internacionais sobre a carreira e o salário do pessoal docente}

É importante fazer referência ao fato de a valorização do magistério ser discutida em termos internacionais, após uma forte desvalorização da profissão docente, ocorrida, principalmente, na segunda metade do século XX. Pierre Furter, na obra "Os sistemas de formação em seus contextos: introdução a um método de educação comparada", resgata uma parte dessa história, ao explanar as articulações realizadas pela OIT e a UNESCO ${ }^{6}$ antes e após organismos proporem a "Recomendación relativa a la situación del personal docente", assinada por 26 membros, em 1966, numa conferência governamental:

Recordemos em primeiro lugar o essencial dessa iniciativa excepcional. A OIT há muito se preocupava com as condições de

6 Organização Internacional do Trabalho (OIT); Organização das Nações Unidas para a Educação, a Ciência e a Cultura (UNESCO).

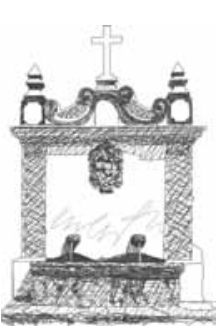


trabalho do corpo docente, considerando [que] a penúria de professores poderia ser conseqüência (sic) de condições insatisfatórias no exercício da profissão. Com a UNESCO e o BIE*, o esforço se desenvolveu durante duas décadas:

1952 - A OIT solicita a constituição de uma comissão consultiva de empregadores e de trabalhadores intelectuais.

1954- A OIT apresenta seu primeiro relatório, que põe em relevo níveis insatisfatórios de remuneração e condições medíocres de emprego. O relatório sugere uma reunião interorganizações.

1958 - A OIT, o BIE e a UNESCO organizam uma reunião tripartite de especialistas que estudam três pontos: os problemas da remuneração; a segurança social; e os problemas sócio-econômicos (sic).

1963 - Uma reunião de especialistas faz um primeiro balanço da discussão, que compreende novos pontos: duração do trabalho; remuneração; folgas; locais e efetivos escolares; cuidados médicos; aposentadoria; alojamento; direito à organização e à participação na definição da política da educação e de formação dos docentes etc.

1964 - Uma conferência tripartite estabelece uma Recomendação sobre a condição do pessoal docente.

1966 - Esta Recomendação é aprovada por unanimidade por uma conferência governamental que compreendia 26 países. Resta ainda ratificá-la, particularmente pelas autoridades suíças. A recomendação cobre o conjunto dos problemas da condição docente, isto é: o preparo do pessoal docente (inclusive sua seleção); seu aperfeiçoamento; as condições de acesso à profissão e a organização de uma carreira profissional (ascensão, promoção, estabilidade no

*BIE ou IBE - International Bureau of Education - Organismo da UNESCO responsável pela organização e produção de informações sobre Educação.

Ano 14 - n. 17 - julho 2011 - p. 129-167 
emprego, medidas disciplinares etc.); os direitos e as obrigações do corpo docente; as condições necessárias para um ensino eficaz $\left(\mathrm{n}^{\circ}\right.$. de alunos por classe, o material didático, as horas de trabalho, as férias, as folgas pagas, o intercâmbio de professores, os edifícios, a situação particular dos professores no meio rural); a segurança social; a penúria dos professores (Lüscher, 1965).

Para que se tenha uma idéia (sic) da distância que existe ainda entre esses objetivos e a realidade, podem ser consultadas diferentes enquêtes sobre a situação do pessoal docente na Europa (OCDE, 1968; Les enseignants, 1965 e 1967).

1970 - Primeiro balanço das conseqüências (sic) dessa Recomendação, mostrando que não se conseguiu avançar em relação a três pontos maiores: as restrições orçamentárias; os problemas de disciplina e de crise de autoridade que provocam fenômenos de aumento de rigidez; e a incerteza do recrutamento.

As aplicações da Recomendação tal como são consignadas nos relatórios das organizações (1970 e 1976) deixam poucas ilusões. Não seria útil, a este respeito, fazer alguns estudos regionais - a exemplo daquele iniciado na AL por Lorenzo (1969) - em que seriam examinadas as aplicações, pelos Estadosmembros, das resoluções tomadas? Estas enquêtes permitiriam melhor confrontar o que se (isto é, a sociedade, o sistema social) espera dos corpos docentes com aquilo que os corpos docentes visam ou desejam realizar a partir de suas formações e do que vivem cotidianamente (FURTER, 1980, p. 236 e 237).

É útil perceber, nessa longa citação, que no período pós-guerra, conhecido como período dos "anos dourados" do desenvolvimento econômico, político e social em termos mundiais, a OIT e a UNESCO já chamavam a atenção mundial para a penúria salarial e as condições de trabalho a que os docentes estavam submetidos

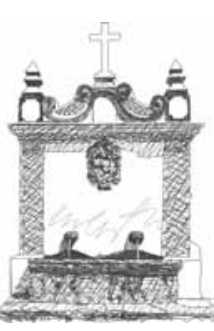


em termos internacionais. Além disso, chama a atenção o destaque que o autor dá ao fato de que, num primeiro balanço do processo de implantação das recomendações, perceberam-se dificuldades por conta de restrições orçamentárias, de crise de autoridade do professor e de recrutamento de docentes.

\section{1- A Recomendação da OIT/UNESCO de 1966}

O reconhecimento da necessidade de os profissionais da Educação terem planos de carreira está presente na "Recomendación relativa a la situación del personal docente", aprovada em 1966. De acordo com os princípios gerais da Recomendação, o progresso e a qualidade da Educação dependeriam "primordialmente das qualificações e competências do corpo docente", e a realização das finalidades e objetivos da Educação exigiria "que os professores desfrutem de uma condição justa e que a profissão docente goze do respeito público que merece" (OIT/UNESCO, 1966, p. 26). Diante disso, a OIT e a UNESCO estabeleceram um conjunto de orientações que deveriam ser consideradas pelos países quando da elaboração dos planos de carreira dos profissionais da Educação Básica do setor público e privado.

Antes de apresentar o conjunto de orientações, o documento esclarece o significado dos termos "pessoal docente" ou professores e "condição docente". Pessoal docente e professores refere-se a toda pessoa encarregada da educação dos alunos. Condição docente refere-se tanto à posição social (competências e condições de trabalho) conferida segundo o grau de importância da função quanto à remuneração e demais benefícios, em comparação com outras profissões.

Os princípios gerais da Recomendação têm como pressuposto que uma educação de qualidade, entendida como direito de todos, demanda qualificações e condições de trabalho que permitam ao pessoal docente a realização de um bom ensino e a dedicação exclusiva às suas funções profissionais. 
Em consonância com os princípios gerais, a Recomendação adverte sobre a importância da participação das organizações dos professores na formulação das políticas educacionais e a observância da não discriminação por razões de raça, cor, sexo, religião, opiniões políticas, origem nacional ou social e situação econômica na formação e contratação do pessoal docente.

Dada a importância dos recursos financeiros para a realização de políticas educacionais que garantam a educação como bem público, fundamental ao desenvolvimento social e individual, a Recomendação sugere que cada país destine parte dos recursos de seus orçamentos para o financiamento da Educação.

Deveria dar-se especial prioridade, nos orçamentos da cada País, à atribuição de uma parte suficiente do rendimento nacional para o desenvolvimento da educação, tendo em conta que o êxito na consecução dos fins e objetivos da educação depende em grande parte dos recursos econômicos com que esta pode contar (OIT/UNESCO, 1966, p. 28-29).

Apesar da importância da indicação de destinação de recursos financeiros públicos para a realização do conjunto de recomendações do documento de 1966, num primeiro balanço sobre sua implantação, realizado em 1970, verificou-se que eles continuavam sendo um limitador à realização das Recomendações (FURTER, 1980, p. 237).

Embora no marco de recomendações gerais, a Recomendação expressava preocupação acerca do tratamento que os países deveriam despender às questões educacionais como política de Estado. O reconhecimento da importância do pessoal docente para a realização do direito à educação é explicitado, entre outras, na discussão sobre a escassez de professores.

As autoridades deveriam reconhecer que o melhoramento da situação econômica e social dos professores, das suas condições de vida e de trabalho, dos termos do seu contrato de trabalho e das suas perspectivas

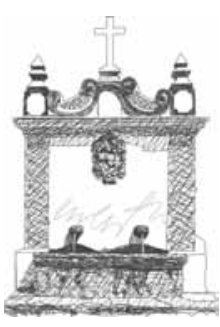


de carreira é o melhor meio de obstar a escassez de professores competentes e experientes e atrair e reter no ensino um número importante de pessoas plenamente qualificadas (OIT/UNESCO, 1966, p. 50).

O documento alerta para a necessidade de as políticas de formação de professores estarem atentas à necessidade de uma formação inicial atrativa, de forma a assegurar um número suficiente de professores com condições acadêmicas adequadas ao exercício do magistério. Para tal, os candidatos a futuros professores deveriam receber bolsas de estudos ${ }^{7}$ que lhes possibilitassem dedicar-se aos estudos e galgar boa formação acadêmica. Além disso, deveria ser assegurado aos egressos dos cursos de formação de professores o acesso a empregos compatíveis com a sua formação.

O documento destaca também como fundamental a garantia de formação continuada para o aperfeiçoamento profissional, com vistas à melhoria do conteúdo e das técnicas pedagógicas do ensino. Ainda, ele sugere a adoção do reconhecimento, em nível internacional, da titulação/formação que assegura o direito à docência, com base em normas aprovadas nos diferentes países. Entretanto, a despeito disso, de acordo com Furter (1980), o recrutamento de docentes também foi apresentado como um dos aspectos com dificuldade para a implantação das Recomendações no balanço de 1970 .

Em relação à carreira profissional, destacam-se os seguintes aspectos:

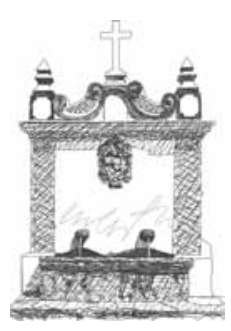

1- Estabelecimento de políticas claras de recrutamento, definidas em acordo com as organizações de professores.

2- Existência de período experimental no início da carreira (estágio probatório).

7 Nesse sentido, é interessante lembrar a experiência dos Centros Específicos de Formação e Aperfeiçoamento do Magistério (CEFAMs), onde se formavam professores em nível médio com Habilitação Específica para o Magistério, que na década de 1980 e 1990 em São Paulo tinham um projeto pedagógico claramente definido e funcionavam em período integral com 
3- Possibilidade de ascensão e promoção profissional, de acordo com as qualificações requeridas.

4- Critérios objetivos para as promoções, devidamente negociados com as organizações dos professores.

5- Estabilidade e segurança no emprego.

6- Participação de pessoas da mesma categoria profissional no julgamento de medidas disciplinares.

7- Reconhecimento da jornada de trabalho em tempo parcial.

8- Liberdade acadêmica aos professores.

9- Realização de consultas às organizações dos professores sobre: política educacional, organização escolar e mudanças no sistema de ensino.

10-Negociações entre as organizações de professores e as entidades patronais para o estabelecimento da remuneração e das condições de trabalho dos professores.

11-Número adequado de alunos por turma, de forma que o professor possa prestar atenção às necessidades e às dificuldades de cada um.

12-Jornada de trabalho do professor, tendo em conta os diversos fatores que determinam o volume de trabalho:
a) o número de alunos de que se ocupará por dia e por semana;
b) o tempo que se considera necessário para a boa preparação das aulas e correção dos exercícios;
c) o número de cursos diferentes a dar por dia; d) o tempo exigido ao professor para participar em pesquisas, em atividades extracurriculares e para supervisar e orientar os alunos;
e) o tempo que seria desejável aos professores para informar os pais dos alunos ou encarregados de educação do progresso dos alunos (OIT/UNESCO, 1966, p. 40).

13-Composição da jornada prevendo horas destinadas ao aperfeiçoamento profissional.

14-Licenças com remuneração total ou parcial para realização de estudos. Os períodos de licença para estudos devem contar para

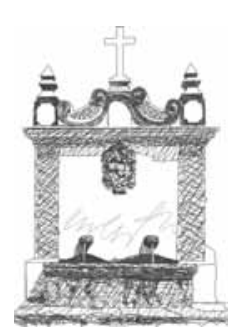

137 
fins de antiguidade e aposentadoria.

15-Licenças pagas para participação nas atividades das organizações dos professores.

16-Direito à licença por doença e maternidade. Licença suplementar, não remunerada de, no máximo, um ano para as professoras com filhos (OIT/UNESCO, 1966).

De fato, ainda atualmente (2011), poder-se-ia afirmar que esse conjunto de recomendações, caso realmente observado, poderia concorrer positivamente para a construção de planos de carreira que atenderiam as demandas da profissão, numa perspectiva de valorização do magistério. Infelizmente, pouco foi realmente discutido e estabelecido no que se refere à legislação brasileira sobre a condição docente nas últimas décadas.

Em relação à remuneração dos professores, na Recomendação são feitas as seguintes orientações:

1- Os professores devem ter remuneração similar à de outras profissões que exijam qualificações equivalentes ou análogas. (Grifos nossos) 2- A remuneração de professores em período probatório ou em regime de contrato temporário não deve ser inferior à dos professores titulares.

3- A remuneração dos professores deve assegurar-lhes para si e seus familiares a manutenção de um bom nível de vida e permitir a continuidade de sua formação e aperfeiçoamento profissional.

4- As diferenças na remuneração devem ser baseadas em critérios objetivos, tais como: "nível de qualificação, anos de experiência ou grau de responsabilidade". A maior e a menor remuneração devem ser mantidas dentro de limites aceitáveis. (OIT/UNESCO, 1966, p. 45) 5- O intervalo para aumento da remuneração no interior de cada categoria deve respeitar intervalos regulares, de preferência anuais. 6- “A progressão da remuneração entre o mínimo e o máximo da escala estabelecida não deveria exceder um período de 10 a 15 anos". (OIT/UNESCO, 1966, p. 45)

7- Os professores em período experimental ou contratados temporariamente devem ter aumento da remuneração de 
forma periódica.

8- A remuneração dos professores deve sofrer revisões periódicas tendo em vista o aumento do custo de vida, a elevação do nível de vida geral e o aumento generalizado de salários e remuneração. 9- "Não deveria ser instituído ou aplicado sistema algum de remuneração com base no mérito, sem prévia consulta e aceitação por parte das organizações do pessoal docente interessadas". (OIT/UNESCO, 1966, p. 45, 46).

Novamente, algumas questões sobre a remuneração dos professores chamam a atenção se comparadas às práticas ou às discussões atuais. Entre elas, destaca-se a questão da remuneração por mérito, pois a Recomendação já definia uma perspectiva muito distinta das que são apresentadas como "novidades" nas legislações mais recentes em vários sistemas educacionais no Brasil (que estão sendo implantadas sem qualquer discussão com as organizações docentes) e que geralmente implicam a "culpabilização" dos professores sobre a questão da qualidade da Educação.

\subsection{Orientações internacionais das Conferências Mundiais de Jomtien (1990) e Dakar (2000)}

Outros documentos internacionais também trouxeram contribuições para a questão da carreira e da remuneração docente.

A “Declaração Mundial sobre Educação para Todos", aprovada pela Conferência Mundial sobre Educação para Todos, realizada em Jomtien, Tailândia, de 5 a 9 de março de 1990, que almejava a satisfação das necessidades básicas de aprendizagem, ao mesmo tempo estabelecia, no art. $7^{\circ}$, que as autoridades responsáveis pela Educação dos níveis nacional, estadual e municipal tinham a obrigação prioritária de proporcionar educação básica para todos, em articulação com diferentes setores sociais, destacava, nessa articulação

o papel especial dos professores, dos administradores e do pessoal que trabalha em educação; entre os órgãos educacionais

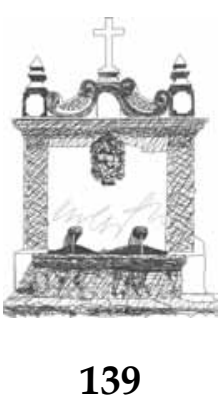


e demais órgãos de governo, incluindo os de planejamento, finanças, trabalho, comunicações, e outros setores sociais; [...]. É particularmente importante reconhecer o papel vital dos educadores e das famílias. Neste contexto, as condições de trabalho e a situação social do pessoal docente, elementos decisivos no sentido de se implementar a educação para todos, devem ser urgentemente melhoradas em todos os países signatários da Recomendação Relativa à Situação do Pessoal Docente OIT/UNESCO (1966). (UNESCO, 1998).

No artigo 21, no qual são definidas as estratégias específicas orientadas concretamente para melhorar as condições de escolaridade, entre outras medidas, indicava que a

formação dos educadores deve estar em consonância aos resultados pretendidos, permitindo que eles se beneficiem simultaneamente dos programas de capacitação em serviço e outros incentivos relacionados à obtenção desses resultados; currículo e avaliações devem refletir uma variedade de critérios, enquanto que os materiais, inclusive a rede física e as instalações, devem seguir a mesma orientação. Em alguns países, a estratégia deve incluir mecanismos para aperfeiçoar as condições de ensino e aprendizagem, de modo a reduzir o absenteísmo e ampliar o tempo de aprendizagem (UNESCO, 1998).

Porém é no artigo 33 que a Declaração reconhece, com todas as letras, a importância da carreira e da remuneração docente para a implantação de uma educação de qualidade:

O proeminente papel do professor e demais profissionais da educação no provimento de educação básica de qualidade deverá ser reconhecido e desenvolvido, de forma a otimizar sua contribuição. Isso irá implicar a adoção de medidas para garantir o respeito

Ano 14 - n. 17 - julho 2011 - p. 129-167 
aos seus direitos sindicais e liberdades profissionais e melhorar suas condições e status de trabalho, principalmente em relação à sua contratação, formação inicial, capacitação em serviço, remuneração e possibilidades de desenvolvimento na carreira docente, bem como para permitir ao pessoal docente a plena satisfação de suas aspirações e o cumprimento satisfatório de suas obrigações sociais e responsabilidades éticas (UNESCO, 1998).

Dez anos depois, a "Cúpula Mundial de Educação", realizada em Dakar, Senegal, de 26 a 28 de abril de 2000, em seu documento final, ofereceu bem menos indicações a respeito da condição docente - talvez porque não reforçasse a Declaração de Jomtien indicando uma mudança mundial de rumos -, pois somente no artigo $8^{\circ}$ faz alguma menção explícita - em termos muito genéricos e aparentemente descontextualizados - quanto aos compromissos dos governos, organizações, agências, grupos e associações representadas na Cúpula Mundial de Educação para atingir seus objetivos da seguinte forma:

[...] iv. desenvolver sistemas de administração e de gestão educacional que sejam participativos e capazes de dar resposta e de prestar contas; [...]

viii. criar ambientes seguros, saudáveis, inclusivos e eqüitativamente (sic) supridos, que conduzam à excelência na aprendizagem e níveis de desempenho claramente definidos para todos; [...] ix. melhorar o status, a auto-estima (sic) e o profissionalismo dos professores; [...] (UNESCO, 2000, p. 2).

Nota-se no documento final de 2000 a falta de menção ao reforço ou à explicitação da necessidade de planos de carreira ou de remuneração digna para os docentes, ou seja, aconselha, apenas de modo genérico, a "melhorar o status, a autoestima e o profissionalismo dos professores".

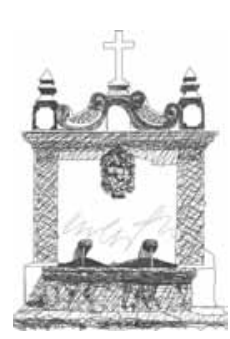




\section{2- Breve exposição histórica sobre planos de carreira e de salários do magistério na legislação nacional}

Sem pretender esgotar toda a rica documentação e estudos sobre a temática, é possível se afirmar que não é matéria recente que alguns elementos que constituem o que se configuram atualmente, como plano de carreira e de remuneração docente, estejam presentes na legislação nacional.

Já na primeira lei de Educação do país - a que mandava "criar escolas de primeiras letras em todas as cidades, vilas e lugares mais populosos do Império" -, que foi estabelecida por Decreto Imperial $^{8}$ de D. Pedro I, em 15 de outubro de 1827 (vem daí a data de comemoração do Dia do Professor ${ }^{9}$ ), havia vários elementos interessantes quanto à ideia de uma carreira e de salário docente. Entre eles, alguns se destacam:

- No artigo $3^{\circ}$ já se afirmava quanto à questão salarial que: “os presidentes, em Conselho, taxarão interinamente os ordenados dos Professores, regulando-os de $200 \$ 000$ a 500\$000 anuais ${ }^{10}$, com atenção às circunstâncias da população e carestia dos lugares, e o farão presente a Assembléia Geral para a aprovação" (BRASIL, 1827).

- Quanto à questão da formação inicial: "os Professores que não

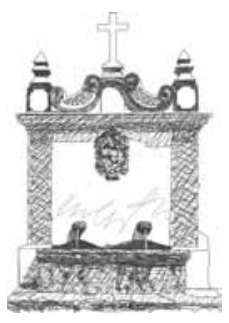

142

8 Obtido no endereço: http://www.adur-rj.org.br/5com/pop-up/decreto-lei_imperial.htm, acessado em 20/10/2010.

9 “[...] O Deputado Estadual Paulista, Dr. Antonio Carlos de Salles Filho, no mandato 1947/51, é o autor do Projeto de Lei que instituiu tal homenagem, em âmbito do território do Estado de São Paulo e, mais tarde, já como Deputado Federal, no mandato 1955/59, o fez com espectro e abrangência nacional, passando os abnegados professores a, pelo menos isto, terem seu dia especial, 15 de outubro [...]", informação disponível em http://www.arteducacao.pro.br/ homenagem/queridomestre.htm, acesso em 20/12/2010.

10 No site http://www.arteducacao.pro.br/homenagem/queridomestre.htm, acessado em 20/12/2010, o professor Vicente Martins, da Universidade Estadual Vale do Acarau, Sobral(CE), afirma que o "economista Antônio Luiz Monteiro Coelho da Costa, especialista em cotação de moedas, atendendo à solicitação dos autores, por e-mail, fez a conversão dos réis, de 1827, em reais, de 2001 (discutíveis), e, segundo Luiz Monteiro, 200\$000 equivaleriam a aproximadamente $\mathrm{R} \$ 8.800,00$, isto é, a um salário mensal de $\mathrm{R} \$ 680$ (considerando o $13^{\circ}$ ), e $500 \$ 000$ a aproximadamente R\$ 22.000 (R\$ 1.700 por mês)." Em termos de valores em Reais de julho de 2010, corrigido pelo INPC do IBGE (mesmo indicador econômico do Fundeb), isso representaria $\mathrm{R} \$ 18.592,35$ no ano ou $\mathrm{R} \$ 1.407,10$ por mês no menor valor e $\mathrm{R} \$ 46.480,87$ no ano e $\mathrm{R} \$ 3.575,45$ por mês no maior valor.

Ano 14 - n. 17 - julho 2011 - p. 129-167 
tiverem a necessária instrução deste ensino, irão instruir-se em curto prazo e à custa dos seus ordenados nas escolas das capitais" (BRASIL, 1827).

- Quanto à questão do processo de seleção de candidatos ao cargo de professor, estabelecia no artigo $7^{\circ}$ : "os que pretenderem ser providos nas cadeiras serão examinados publicamente perante os Presidentes, em Conselho; e estes proverão o que for julgado mais digno e darão parte ao Governo para sua legal nomeação" (BRASIL, 1827).

- As condições legais para a contratação de professor exigiam que só fossem "admitidos à oposição e examinados os cidadãos brasileiros que estiverem no gozo de seus direitos civis e políticos, sem nota na regularidade de sua conduta" (BRASIL, 1827).

- Bem como reforçava a ideia da necessidade de aprovação em "concurso público" quando estabelecia no artigo $9^{\circ}$ que: "os Professores atuais não serão providos nas cadeiras que novamente se criarem, sem exame de aprovação, na forma do Art. $7^{0 \prime \prime}$ (BRASIL, 1827).

- Pode-se entender como uma "antecipação histórica" das atuais gratificações e "avaliações de desempenho" do trabalho docente o que estava preconizado no artigo 10, ou seja: “os Presidentes, em Conselho, ficam autorizados a conceder uma gratificação anual que não exceda à terça parte do ordenado, àqueles Professores, que por mais de doze anos de exercício não interrompido se tiverem distinguido por sua prudência, desvelos, grande número e aproveitamento de discípulos" (BRASIL, 1827).

- Na mesma lei não haveria discriminação de gênero, (grifos nossos) pois previa que "as Mestras vencerão os mesmos ordenados e gratificações concedidas aos Mestres" (BRASIL, 1827).

- A garantia de irredutibilidade de salário e de "estabilidade" no emprego estavam dispostas no artigo 14, quando ele assegurava: “Os provimentos dos Professores e Mestres serão vitalícios; mas os Presidentes em Conselho, a quem pertence a fiscalização das escolas, os poderão suspender e só por sentenças serão demitidos,

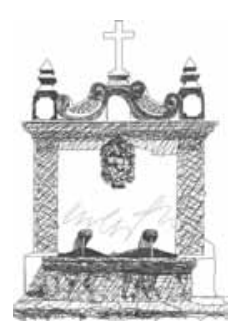


provendo interinamente quem substitua" (BRASIL, 1827).

No decorrer do Império (D. Pedro I e D. Pedro II), várias reformas da incipiente Educação Nacional foram propostas (em geral no âmbito do Governo Geral para as Províncias). Entre elas constavam diferentes medidas que tentavam dar conta da condição do trabalho docente, em particular as que buscavam estabelecer garantias de remuneração, formação inicial, regras para processos de seleção, entre outras, para a realização do trabalho do professor nas escolas públicas.

Uma rápida visão sobre alguns artigos das Constituições Federais do período Republicano também pode nos fornecer alguns dos elementos presentes, ainda hoje, em planos de carreira e salários de professores.

A primeira Constituição da República, a dos Estados Unidos do Brasil, de 1891, pouco abordou a questão da Educação Pública Nacional, porém estabeleceu em sua Declaração de Direitos, mais precisamente no $\S 6^{\circ}$ do artigo 72 , que "será leigo o ensino ministrado nos estabelecimentos públicos", como uma clara demarcação sobre a posição do Estado em relação à Igreja. Ao compreender a ação docente numa perspectiva liberal e aberta a todos os brasileiros, como forma de seleção de cargos públicos, pode-se entender que aquela Constituição consagrou a ação docente, no § 24 do mesmo artigo, por meio da expressão "é garantido o livre exercício de qualquer profissão moral, intelectual e industrial", bem como no artigo 73, ao estabelecer que "os cargos públicos civis ou militares são acessíveis a todos os brasileiros, observadas as condições de capacidade especial que a lei estatuir, sendo, porém, vedadas as acumulações remuneradas".

Já a Constituição de 1934 se apresenta com grande aproximação à temática da Educação Nacional, certamente sob a influência do documento que veio a ser conhecido como "Manifesto dos Pioneiros" de 1932. Esse documento representava, na prática, uma grande proposta de Plano Nacional de Educação (o qual está, pela primeira vez, previsto na Constituição de 1934). Nela estão 
expressos vários artigos, incisos, parágrafos e alíneas a respeito da questão educacional (destaca-se inclusive a primeira vinculação constitucional de recursos para a educação) e, no que diz respeito à questão da condição docente, faz algumas menções específicas: - No capítulo "Dos Direitos e das Garantias Individuais", é apresentada, no artigo 36, a interessante determinação de que "nenhum imposto gravará diretamente a profissão de escritor, jornalista ou professor" (grifo nosso).

- No parágrafo único do artigo 150, que previa que “O plano nacional de educação constante de lei federal [...] obedecerá às seguintes normas:" havia alíneas específicas relativas ao trabalho docente onde dispunha: “c) liberdade de ensino em todos os graus e ramos, observadas as prescrições da legislação federal e da estadual"; [...]; e) limitação da matrícula à capacidade didática do estabelecimento [...]; f) reconhecimento dos estabelecimentos particulares de ensino somente quando assegurarem a seus professores a estabilidade, enquanto bem servirem e uma remuneração condigna" (grifos nossos).

- No artigo 155 estabelecia-se que "é garantida a liberdade de cátedra".

- A forma de seleção de docentes, prevista no artigo 158, situava a obrigatoriedade dos concursos para o magistério oficial, as exceções, entendidas como as contratações temporárias verificadas até hoje nas redes públicas - e as garantias oferecidas para o exercício do cargo, da seguinte forma:

É vedada a dispensa do concurso de títulos e provas no provimento dos cargos do magistério oficial, bem como, em qualquer curso, a de provas escolares de habilitação, determinadas em lei ou regulamento. $\S 1^{\circ}$ Podem, todavia, ser contratados, por tempo certo, professores de nomeada, nacionais ou estrangeiros. $\S 2^{\circ}-$ Aos professores nomeados por concurso para os institutos oficiais cabem as garantias de vitaliciedade e de inamovibilidade nos cargos, sem prejuízo do disposto no Título VII. Em casos

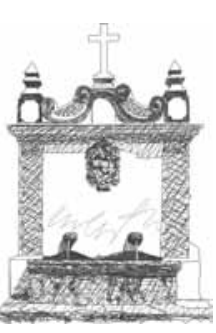

145 
de extinção da cadeira, será o professor aproveitado na regência de outra, em que se mostre habilitado (BRASIL, 1934, art. 158).

Completando essas disposições, há no capítulo “dos Funcionários Públicos" uma série de elementos que também irão compor direitos dos quadros docentes das redes públicas, tais como: estabilidade; ingresso exclusivo por concurso público; férias; licenças, procedimentos nos casos de aposentadoria e invalidez; vedação de acúmulo de cargos; necessidade de estabelecimento de estatutos que consolidassem seus direitos e deveres, entre outros. É nesse capítulo que também se encontra a disposição sobre acúmulo de cargos públicos e que diz respeito diretamente ao professor, pois definia: "Excetuam-se os cargos do magistério e técnicocientíficos, que poderão ser exercidos cumulativamente, ainda que por funcionário administrativo, desde que haja compatibilidade dos horários de serviço" (BRASIL, 1934).

Na Constituição de 1937, outorgada por Getúlio Vargas, que estabeleceu a Ditadura do Estado Novo, o número de itens relativos à Educação Nacional foi bem menos significativo. Embora destacasse que era dever da União, dos estados e municípios suprir aos que não apresentassem recursos suficientes, não havia mais a garantia de recursos vinculados para a Educação. Esse documento não possuía mais a ideia de elaborar e implantar um Plano Nacional de Educação, entre outros dispositivos anteriores. Apesar de também existir um capítulo para a Educação Nacional, praticamente não havia menções a quaisquer direitos dos professores, a não ser o fato de que o Ensino Religioso não poderia "constituir objeto de obrigação dos mestres ou professores, nem de frequência compulsória por parte dos alunos". Quanto aos dispositivos relativos ao funcionalismo público, a Constituição de 1937 praticamente repete os itens presentes na Constituição de 1934, com a exceção de que no artigo 159 se estabelece claramente que é vedada a acumulação de cargos públicos remunerados da União, dos estados e dos municípios.

Na Constituição de 1946 é retomado um número de importantes 
aspectos relativos à Educação Nacional, já presentes na Constituição de 1934. Alguns desses aspectos são a vinculação constitucional, a inspiração na liberdade e nos ideais da solidariedade humana, a obrigatoriedade, a gratuidade, entre outros. Quanto à condição docente, no artigo 168, inciso IV, previa-se que

as empresas industriais e comerciais são obrigadas a ministrar, em cooperação, aprendizagem aos seus trabalhadores menores, pela forma que a lei estabelecer, respeitados os direitos dos professores;[...] VI - para o provimento das cátedras, no ensino secundário oficial e no superior oficial ou livre, exigir-se-á concurso de títulos e provas. Aos professores, admitidos por concurso de títulos e provas, será assegurada a vitaliciedade; VII - é garantida a liberdade de cátedra (BRASIL, 1946, art. 168). (grifos nossos)

No capítulo “dos Funcionários Públicos”, artigos 185 e 186, além de diversos direitos e responsabilidades definidas, também se fazia menção à possibilidade de acúmulo de cargos pelo magistério, dentro das condições estabelecidas - dois cargos de magistério ou um de magistério com outro técnico ou científico -, contanto que houvesse correlação de matérias e compatibilidade de horário, bem como se definia que a "primeira investidura em cargo de carreira e em outros que a Lei determinar efetuar-se-á mediante concurso, precedendo inspeção de saúde". No artigo 203, destacava-se ainda que "nenhum imposto gravará diretamente os direitos de autor, nem a remuneração de professores e jornalistas" (BRASIL, 1946).

Ainda com relação a salário dos professores, a Lei Orgânica do Ensino Normal, Decreto-Lei n. 8.530 de 1994, previa que "aos professores de ensino normal será assegurado remuneração condigna" (artigo 49). Ela também previa que o provimento dos professores em caráter efetivo deveria ser por meio de concurso público.

A Lei Orgânica do ensino primário, Decreto-Lei n. 8.529, de 1946, não fazia referência ao salário e à carreira dos professores, mas estabelecia, no artigo 35, que “os poderes públicos

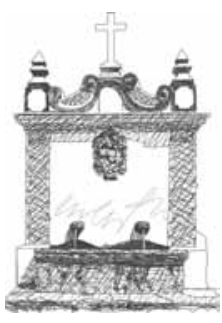

147 
providenciarão no sentido de obterem contínuo aperfeiçoamento técnico do professorado das suas escolas primárias".

A Constituição de 1967, a da República Federativa do Brasil, promulgada simultaneamente pelas Mesas das Casas do Congresso Nacional (estabelecida em período ditatorial militar), definiu que cabia à União estabelecer o Plano Nacional de Educação (e de Saúde) e legislar sobre as diretrizes e bases da Educação Nacional e as condições de capacidade para o exercício das profissões liberais e técnico-científicas. Em termos do funcionalismo público, entre outras disposições, estabelecia a necessidade de concursos públicos e admitia o acúmulo de cargos (artigo 97) somente nos casos de juiz e um cargo de professor, de dois cargos de professor e de um cargo de professor com outro técnico ou científico. No capítulo da Educação, além de não mais estabelecer a vinculação constitucional, permitir o acesso a verbas públicas ao setor privado, definir que o acesso aos níveis posteriores ao primário seria gratuito somente para aqueles que demonstrassem falta de recursos, entre outras disposições, no que diz respeito aos docentes, ela estabelecia como um de seus princípios que "o provimento dos cargos iniciais e finais das carreiras do magistério de grau médio e superior será feito, sempre, mediante prova de habilitação, consistindo em concurso público de provas e títulos quando se tratar de ensino oficial" (inciso V) e, contraditoriamente, o inciso VI garantia a liberdade de cátedra.

Numa condição de excepcionalidade, a Emenda Constitucional n. 1, de 1969, outorgada por uma junta militar que se utilizou das atribuições que lhes conferia o artigo $3^{\circ}$ do Ato Institucional n. 16, de 14 de outubro de 1969 , combinado com o $\S 1^{\circ}$ do artigo $2^{\circ}$ do Ato Institucional n. 5, de 13 de dezembro de 1968, provocou pouca mudança nos dispositivos constitucionais relativos à Educação. Há, inclusive, a manutenção de praticamente as mesmas condições para o funcionalismo (já apresentadas anteriormente) que também alcançavam o magistério. Além disso, no inciso VI do § 3 do artigo 176, estava repetido o que constava na Constituição de 1967 a 
respeito do provimento de cargos via concurso. No entanto, no inciso VII do mesmo artigo estabeleceu-se de modo explícito "a liberdade de comunicação de conhecimentos no exercício do magistério, ressalvado o disposto no art. 154", alterando o conceito de liberdade de cátedra vigente desde 1934, pois ao se verificar o conteúdo do artigo 154, encontra-se o seguinte:

$\mathrm{O}$ abuso de direito individual ou político, com o propósito de subversão do regime democrático ou de corrupção, importará a suspensão daqueles direitos de dois a dez anos, a qual será declarada pelo Supremo Tribunal Federal, mediante representação do Procurador Geral da República, sem prejuízo da ação cível ou penal que couber, assegurada ao paciente ampla defesa (BRASIL, 1969).

Sem retornar demasiadamente ao passado, na legislação infraconstitucional, em termos nacionais, na primeira Lei de Diretrizes e Bases da Educação Nacional (lei n. 4024/61) previamse alguns aspectos relativos à carreira e à remuneração docente. Logo de início, no artigo 16, estabelece-se como uma das condições para o reconhecimento do funcionamento dos estabelecimentos pelos sistemas de ensino a "garantia de remuneração condigna aos professores". Na Lei há diferentes destaques quanto à questão da formação inicial para a docência e para as demais funções de magistério. Porém, de modo alternativo à necessidade de estatutos e regimes jurídicos ligados à esfera estatal para a incumbência do ensino público, no artigo 21 estava previsto que o ensino, em todos os graus, "poderia ser ministrado em escolas públicas, mantidas por fundações cujo patrimônio e dotações sejam provenientes do Poder Público, ficando o pessoal que nelas servir, sujeito, exclusivamente, às leis trabalhistas"' (BRASIL, 1961, art. 21).

Há ainda na Lei um grande destaque quanto à necessidade de registro de professores, mantido pelo Ministério da Educação e Cultura. Entretanto, não há menção explícita à necessidade de planos de carreira e de remuneração para o magistério oficial.

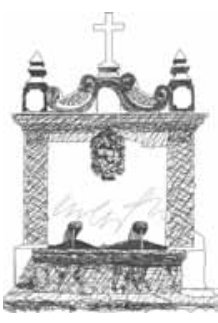


Somente no artigo 60 estava fixado que "o provimento efetivo em cargo de professor nos estabelecimentos oficiais de ensino médio seria feito por meio de concurso de títulos e provas" e que o "magistério nos estabelecimentos de ensino médio só poderia ser exercido por professôres (sic) registrados no órgão competente" (BRASIL, 1961, art. 61).

Na mesma Lei (BRASIL, 1961), no capítulo relativo ao financiamento da Educação, há dispositivos que resguardam recursos para a ação docente, na medida em que considerava como despesas de Educação as verbas utilizadas para o aperfeiçoamento de professores, incentivo à pesquisa e realização de congressos e conferências, bem como prescrevia a União como responsável pela cooperação financeira ao ensino sob a forma de assistência técnica, mediante convênio visando ao aperfeiçoamento do magistério, à pesquisa pedagógica e à promoção de congressos e seminários.

Na lei 5.692/71, os aspectos ligados à carreira, ao salário e ao financiamento da condição docente estão muito mais explícitos. Nela estão contemplados os aspectos ligados à formação inicial dos professores e das demais funções de magistério que se apresenta articulada ao modelo de formação superior estabelecido pela lei 5.540/68. Essa lei trata das licenciaturas curtas, licenciaturas plenas, departamentalização, sistemas de créditos, entre outros, bem como dos registros profissionais exigidos e mantidos pelo MEC conforme o artigo 40, que determinava que "será condição para exercício de magistério ou especialidade pedagógica o registro profissional, em órgão do Ministério da Educação e Cultura, dos titulares sujeitos à formação de grau superior" (BRASIL, 1971, art. 40).

Na lei 5.692/71, há outros artigos importantes a serem lembrados. A título de exemplificação, no artigo 34 estava previsto que a admissão de professores e especialistas no ensino oficial de $1^{\circ}$ e $2^{\circ}$ graus seria feito "por concurso público de provas e títulos, obedecidas para inscrição as exigências de formação" constantes da própria Lei. $\mathrm{O}$ artigo 35 definiu que "não haveria 
qualquer distinção, para efeitos didáticos e técnicos, entre os professores e especialistas subordinados ao regime das leis do trabalho e os admitidos no regime do serviço público." (BRASIL, 1971). De modo muito claro, no artigo 36, havia o dispositivo que determinava que em cada sistema de ensino haveria "um estatuto que estruture a carreira de magistério de $1^{\circ}$ e $2^{\circ}$ graus, com acessos graduais e sucessivos, regulamentando as disposições específicas da presente Lei e complementando-as no quadro da organização própria do sistema" (BRASIL, 1971, art. 36), e para a rede privada estabelecia, no artigo 37 , que ela deveria obedecer “às disposições específicas desta Lei, às normas constantes obrigatòriamente (sic) dos respectivos regimentos e ao regime das Leis do Trabalho". No artigo 38, previa-se que "os sistemas de ensino estimularão, mediante planejamento apropriado, o aperfeiçoamento e atualização constantes dos seus professores e especialistas de Educação" e, finalmente, determinava-se que os sistemas de ensino deveriam "fixar a remuneração dos professores e especialistas de ensino de $1^{\circ}$ e $2^{\circ}$ graus, tendo em vista a maior qualificação em cursos e estágios de formação, aperfeiçoamento ou especialização, sem distinção de graus escolares em que atuem" (BRASIL, 1971, art. 39).

Caso houvesse alguma condição que prejudicasse o professor, com o estabelecimento da lei 5.692/71, o artigo 86 garantia que ficariam "assegurados os direitos dos atuais professores, com registro definitivo no Ministério da Educação, antes da vigência desta Lei" (BRASIL, 1971, art. 86). Inclusive no que diz respeito ao auxílio financeiro da União aos sistemas estaduais de ensino, havia certas condicionalidades, pois esses sistemas deveriam propor planos com duração de quatro anos, aprovados pelos respectivos Conselhos de Educação e em consonância ao planejamento nacional da Educação. Os recursos então viriam para corrigir as diferenças regionais, tendo em conta, também, o respectivo estatuto do magistério, bem como a remuneração condigna e pontual dos professores.

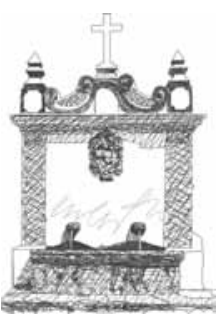




\section{3- Os planos de carreira, cargos e salários dos profissionais da Educação Básica na legislação brasileira pós $\mathrm{CF} / 88$}

A valorização dos profissionais da Educação, como um dos princípios sob os quais o ensino deve ser ministrado, foi consolidada na Constituição Federal de 1988 (CF/88). Entende-se, assim, que a existência de planos de carreira do magistério público constitui aspecto importante na realização do direito à Educação. $\mathrm{O}$ artigo 206, inciso $\mathrm{V}$, da CF/ 88 diz que:

O ensino será ministrado com base nos seguintes princípios:

$[\ldots]$

V- valorização dos profissionais do ensino, garantido, na forma da lei, plano de carreira para o magistério público, com piso salarial profissional e ingresso exclusivamente por concurso público de provas e títulos, assegurado regime jurídico único para todas as instituições mantidas pela União (BRASIL, 1988, art. 206).

Em 1998, a Emenda Constitucional n. 19/98 modificou o inciso $\mathrm{V}$ do art. 206, no que se refere ao regime jurídico único para as instituições de responsabilidade da União, mantendo, no entanto, a necessidade de estados e municípios elaborarem planos de carreira para os profissionais do ensino.

O ensino deve ser ministrado com base nos seguintes princípios:

$[\ldots]$

V- Valorização dos profissionais do ensino, garantidos, na forma da lei, planos de carreira para o magistério público, com piso salarial profissional e ingresso exclusivamente por concurso público de provas e títulos (BRASIL, 1998, art. 206).

A Emenda Constitucional n. 14, de 24 de dezembro de 1996 (EC 14/96), deu nova redação ao artigo 60 do Ato das Disposições 
Constitucionais Transitórias da CF/88, estabelecendo o ensino fundamental como prioridade e destinando, no mínimo, $60 \%$ dos recursos que financiam a Educação à manutenção e desenvolvimento do ensino fundamental.

Nos dez primeiros anos da promulgação desta Emenda, os Estados, o Distrito Federal e os municípios destinarão não menos de sessenta por cento dos recursos que se refere o caput do art. 212 da Constituição Federal à manutenção e ao desenvolvimento do ensino fundamental, com o objetivo de assegurar a universalização de seu atendimento e a remuneração condigna do magistério (BRASIL, 1996).

Além disso, a lei n. 9.424/96, que regulamentou o Fundo de Manutenção e Desenvolvimento do Ensino Fundamental e de Valorização do Magistério (Fundef) - alegando estabelecer mais valorização do magistério -, estabeleceu no artigo $7^{\circ}$ que dos impostos que viriam a compor o fundo, incluída a complementação da União, quando for o caso, "serão utilizados pelos Estados, Distrito Federal e municípios, assegurados, pelo menos, $60 \%$ para a remuneração dos profissionais do Magistério em efetivo exercício de suas atividades no ensino fundamental público" (BRASIL, 1996, art. 7).

A mesma Lei estabeleceu prazo para que estados, municípios e Distrito Federal elaborassem novos planos de carreira para o magistério.

Art. $9^{\circ}$ - Os Estados, o Distrito Federal e os municípios deverão, no prazo de seis meses da vigência desta Lei, dispor de novo Plano de Carreira e Remuneração do Magistério, de modo a assegurar:

I- a remuneração condigna dos professores do ensino fundamental público, em efetivo exercício no Magistério;

II- o estímulo ao trabalho em sala de aula; III- a melhoria da qualidade do ensino.

$\S 1^{\circ}$-Os novos planos de carreira e remuneração

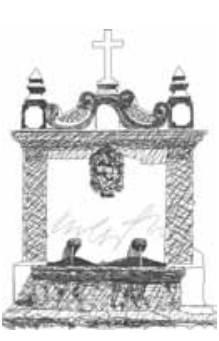


do Magistério deverão contemplar investimentos na capacitação dos professores leigos, os quais passarão a integrar quadro em extinção, de duração de cinco anos.

$\S 2^{\circ}-$ Aos professores leigos é assegurado prazo de cinco anos para a obtenção da habilitação necessária ao exercício das atividades docentes.

$\S 3^{\circ}$ - A habilitação a que se refere o parágrafo anterior é condição para ingresso no quadro permanente da carreira conforme os novos planos de carreira e remuneração (BRASIL, 1996).

Esse prazo não foi necessariamente cumprido por todos os estados e municípios, mas a tentativa era, mais uma vez, de gerar a necessidade dos entes federados de elaborarem planos de carreira para os profissionais de suas redes de ensino, o que tem sido feito a muito custo, de forma paulatina, nas últimas décadas. Ainda em relação à questão do plano de carreira, o artigo 10 da lei n. 9.424/96 estabelece que "Os Estados, o Distrito Federal e os municípios deverão comprovar: [...] II- apresentação de Plano de Carreira e Remuneração do Magistério, de acordo com as diretrizes emanadas do Conselho Nacional de Educação, no prazo referido no artigo anterior" [...].

Além do exposto na CF/88, a valorização dos profissionais da Educação foi tratada na LDB/96 no artigo 67 do Título VI, no qual são estabelecidos os itens que devem ser assegurados nos estatutos e planos de carreira do magistério público:

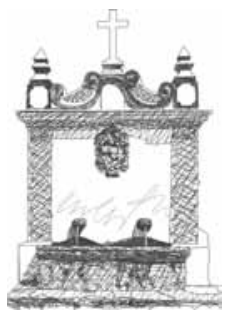

154

I- ingresso exclusivamente por concurso público de provas e títulos;

II- aperfeiçoamento profissional continuado, inclusive com licenciamento periódico remunerado para esse fim;

III- piso salarial profissional;

IV - progressão funcional baseada na titulação ou habilitação e na avaliação de desempenho; $\mathrm{V}$-período reservado a estudos, planejamento e avaliação, incluído na carga de trabalho; VI- condições adequadas de trabalho.

Ano 14 - n. 17 - julho 2011 - p. 129-167 
Parágrafo único - A experiência docente é pré-requisito para o exercício profissional de quaisquer outras funções de magistério, nos termos das normas de cada sistema de ensino (BRASIL, 1996).

Em cumprimento às suas atribuições e ao disposto na $\mathrm{CF} / 88 \mathrm{e}$ na LDB/96, a Câmara de Educação Básica do Conselho Nacional de Educação (CNE/CEB) estabeleceu as "Diretrizes para os novos Planos de Carreira e Remuneração do magistério dos Estados, Municípios e Distrito Federal" por meio da Resolução n. 3, de 8 de outubro de 1997. Nessa Resolução, foram estabelecidos os aspectos que devem ser considerados pelos entes federados, na formulação ou reformulação dos planos de carreira dos profissionais da Educação Básica. No mês anterior, o CNE/CEB havia aprovado o Parecer n. 10/1997, com considerações e justificativas acerca do exposto na Resolução n. 3/97.

Entretanto, antes do Parecer n. 10/97, homologado pelo ministro da Educação, e da Resolução n. 3/97, o CNE/CEB havia aprovado o Parecer n. 2, de 26 de fevereiro de 1997, cujo relator foi o Conselheiro João Antonio Cabral de Monlevade. Tal Parecer, porém, não foi homologado pelo então ministro da Educação, Paulo Renato Souza, que solicitou novo parecer ao CNE/CEB.

De acordo com o Parecer n. 2/97, estimava-se que o piso salarial nacional mensal do professor poderia estar entre $R \$ 400,00$ e $R \$ 450,00$.

O Piso Salarial, numa perspectiva de carreira de variação de índice 100 para 300, onde o salário médio estaria por volta do índice 200, teria que ser necessariamente inferior a $50 \%$ do salário médio potencial nacional, portanto de $\mathrm{R} \$ 496,80$ para baixo. Os vencimentos iniciais de cada carreira poderão ser maiores, dependendo da arrecadação de cada estado ou município, do perfil dos componentes da carreira e de percentuais maiores de verbas vinculadas à educação. Mas o PSPN, para ser praticável por todos os sistemas, supondo-se a estrutura de suplementação prevista 275

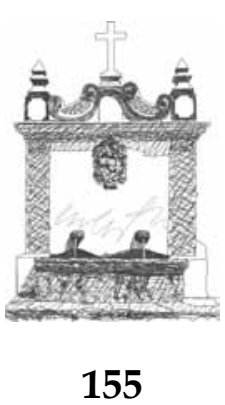


pelo artigo 75 da Lei 9.394/96, que parte da "capacidade de atendimento" de cada sistema referenciado pelo "custo-alunoqualidade", deve-se situar hoje, no nosso entendimento, entre $R \$ 400,00$ e $R \$ 450,00$, para sinalizar alguma valorização do Magistério (BRASIL, 1997, p. 274-275).

No Parecer n. 10/97, a proposta de piso salarial foi estimada num mínimo de $\mathrm{R} \$ 240,00$ e num máximo de $\mathrm{R} \$ 360,00$. Notase que há diferença na compreensão do papel do Estado na valorização do magistério entre os Pareceres, conforme declaração de voto do conselheiro João Monlevade.

O Parecer 02/97 e o texto consensuado no Rio de Janeiro pelos novos redatores da matéria, constante das atas da CEB, embutiam no projeto de Resolução, não como mandamento legal, mas como recomendação política a que se poderiam referir os sistemas de ensino e os sindicatos de trabalhadores da educação, um referencial de vencimento inicial igual ou superior a um Piso Salarial Profissional Nacional que bem poderia se situar com as arrecadações de hoje e com o FVM em R $\$ 500,00$ para jornada de 40 horas semanais com $25 \%$ de horas-atividade, o que elevava o potencial de atendimento de cada professor a 37,5 alunos no conjunto do sistema. E assegurava que a política de valorização do magistério passaria pelo estabelecimento de um custo-aluno qualidade, previsto tanto na LDB como na Lei 9.424/96, que regulamenta o artigo 60 do Ato das Disposições Constitucionais Transitórias da Constituição Federal. Estados e Municípios, obedecida a sua capacidade de atendimento nos termos do artigo 75 da Lei 9.394/96, que pudessem oferecer vencimentos iniciais maiores e proporção maior de horas-atividade, estariam livres e instados a fazê-lo, sem perigo de engessamento administrativo ou inviabilização financeira, pois o projeto de 
Resolução estabelecia limites de progressão na carreira e sinalizava outras formas de financiamento dos inativos da educação, que hoje gravam inexoravelmente os recursos vinculados ao ensino (BRASIL, 1997b, p. 328-329).

Ainda sobre a carreira do magistério e a remuneração docente, o Plano Nacional de Educação, lei n. 10.172/01 (PNE/2001), fruto de intensa disputa de projetos no Congresso Nacional - em que de um lado havia uma proposta elaborada pelos setores organizados da sociedade civil, materializado no denominado Plano Nacional de Educação - Proposta da Sociedade Brasileira, e de outro lado, uma proposta do MEC - propôs timidamente, entre os objetivos e as metas relacionados ao magistério da Educação Básica: a implementação de jornada de tempo integral para o docente, preferencialmente cumprida numa única escola; a destinação de $20 \%$ a $25 \%$ da carga horária dos professores para atividades de preparação de aula, correção de provas e reuniões pedagógicas; salário condigno, competitivo, no mercado de trabalho, com outras ocupações que requerem nível equivalente de formação; garantia, igualmente, de novos níveis de remuneração em todos os sistemas de ensino, com piso salarial próprio, de acordo com as diretrizes estabelecidas pelo Conselho Nacional de Educação, assegurando a promoção por mérito, entre outras medidas.

Em 2006, a Emenda Constitucional n. 53, de 20 de dezembro de 2006 (EC 53/06), que criou o Fundo de Manutenção e Desenvolvimento da Educação Básica e de Valorização dos Profissionais da Educação (Fundeb), deu nova redação ao inciso V do artigo 206 da CF/ 88, mudando a denominação de profissionais do ensino para profissionais da educação e visando a "valorização dos profissionais da educação, garantidos, na forma da lei, planos de carreira, com ingresso exclusivamente por concurso público de provas e títulos, aos da rede pública". Além dessa modificação, a EC 53/06 acrescentou o inciso VII, que trata do Piso Salarial Profissional Nacional (PSPN) para os profissionais da Educação Escolar Pública.

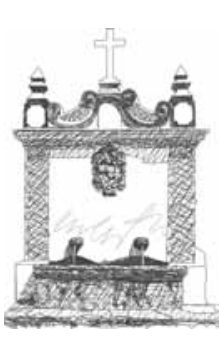


A lei n. 11.494/2006, que regulamenta o Fundeb, determina no artigo 22 que "pelo menos $60 \%$ (sessenta por cento) dos recursos anuais totais dos Fundos serão destinados ao pagamento da remuneração dos profissionais do magistério da educação básica em efetivo exercício na rede pública". Em relação à carreira e ao piso dos profissionais da Educação, estabelece que:

Art. 40. Os Estados, o Distrito Federal e os Municípios deverão implantar Planos de Carreira e remuneração dos profissionais da educação básica, de modo a assegurar: I - a remuneração condigna dos profissionais na educação básica da rede pública;

II - integração entre o trabalho individual e a proposta pedagógica da escola;

III- a melhoria da qualidade do ensino e da aprendizagem.

Parágrafo único. Os Planos de Carreira deverão contemplar capacitação profissional especialmente voltada à formação continuada com vistas à melhoria da qualidade do ensino.

Art. 41. O poder público deverá fixar, em Lei específica, até 31 de agosto de 2007, piso salarial profissional nacional para os profissionais do magistério público da educação básica. (BRASIL, 2007).

Apesar de o prazo estabelecido pela lei n. 11.494/07 ser agosto de 2007, a instituição do PSPN para os profissionais da Educação Básica pública ocorreu somente em 2008, com a lei n. 11.738/08. A Lei estabelece o prazo de um ano para que os Planos de Carreira e Salários sejam adaptados às novas condições previstas. Além

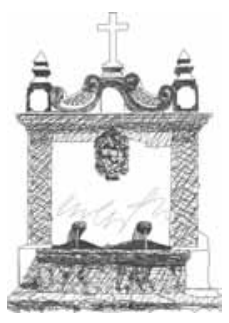
disso, a Lei prevê que

Art. $2^{\circ} \mathrm{O}$ piso salarial profissional nacional para os profissionais do magistério público da educação básica será de $\mathrm{R}$ \$ 950,00 (novecentos e cinquenta reais) mensais, para a formação em nível médio, na modalidade Normal, prevista no art. 62 da Lei $n^{\circ} 9.394$, de 20 de dezembro de 1996, que estabelece as diretrizes e bases da educação nacional. 
$\S 1^{\circ} \mathrm{O}$ piso salarial profissional nacional é o valor abaixo do qual a União, os Estados, o Distrito Federal e os Municípios não poderão fixar o vencimento inicial das Carreiras do magistério público da educação básica, para a jornada de, no máximo, 40 (quarenta) horas semanais.

[...] $\S 4^{\circ} \mathrm{Na}$ composição da jornada de trabalho, observar-se-á o limite máximo de $2 / 3$ (dois terços) da carga horária para o desempenho das atividades de interação com os educandos (BRASIL, 2008).

Infelizmente, após a sanção presidencial à lei 11.738/08, cinco governadores (dos estados do Rio Grande do Sul, Paraná, Santa Catarina, Mato Grosso do Sul e Ceará), com o apoio dos governadores de São Paulo e Minas Gerais, entraram com uma representação de inconstitucionalidade da Lei junto ao Supremo Tribunal Federal (STF), por conta do valor do PSPN e da jornada a ele correspondente, o que retardou ainda mais a aplicação do PSPN. Até o momento, o STF aprovou os valores correspondentes ao PSPN (embora o entendendo como o total da remuneração percebida pelo docente) e ainda não se posicionou quanto à legalidade da jornada a ele correspondente).

Em consideração à EC 53/06 e às leis n. 11.494/07 e 11.738/08 e pareceres anteriores, o CNE/CEB aprovou o Parecer n. 9/2009, que trata da revisão da Resolução n. 3/97 e da Resolução n. 2/2009, que fixa as novas diretrizes para os planos de carreira e remuneração dos profissionais do magistério da Educação Básica.

É com base nessas legislações recentes que estados e municípios devem criar ou reformular os planos de carreira dos profissionais da Educação Básica.

\section{Breves considerações finais}

Para finalizar, é importante ressaltar que houve "mudanças" nas orientações de documentos internacionais, pois enquanto a Recomendação de 1966 era bastante detalhista e rica quanto aos

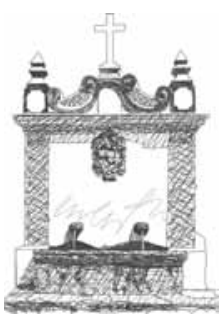

159 
itens e disposições para a implantação de Planos de Carreira e Remuneração para os docentes nos diferentes países, o documento final da Conferência de Dakar de 2000 se apresenta de modo muito genérico, simplificador e pobre no trato da condição docente.

Ressalte-se, também, que elementos do que podemos identificar como necessários ao estabelecimento de Planos de Carreira e Remuneração de professores estão expressos em legislações no Brasil desde o Império, seja em âmbito constitucional ou infraconstitucional.

No caso das disposições constitucionais, percebe-se, quanto à presença de aspectos relativos à condição docente - necessidade de planos de carreira e remuneração para professores - uma dinâmica semelhante às vinculações das verbas para a Educação. Ou seja, nos períodos em que prevaleceram regimes democráticos, foram estabelecidas vinculações de percentuais de impostos para a Educação nas Constituições do país para suprir o conceito de manutenção e desenvolvimento da Educação, conforme já identificado por vários autores como Melchior (1987), Arelaro (1999), Davies (2000), Oliveira (2007), Pinto (2000). Os mesmos períodos foram também aqueles em que se apresentaram de forma mais explícita os aspectos relativos à condição docente nas Constituições do país. Há uma espécie de "paralelo" nessa situação, denotando que nos períodos democráticos há uma ascensão das mobilizações docentes em termos da Educação Nacional, e as inscrições constitucionais, de certa forma, refletem tal configuração política.

Em termos da legislação recente (após a CF/88), as determinações sobre a necessidade de se estabelecer ou rever planos de carreira e remunerações para os docentes foram frequentes, porém os diferentes interesses políticos, econômicos e sociais e a dinâmica das forças políticas em conflito nas diferentes esferas administrativas é que permitem aferir quando e onde eles foram e serão implantados de fato. 


\section{Referências}

ARELARO, L. R. Financiamento e qualidade da educação brasileira: algumas reflexões sobre o documento "Balanço do primeiro ano do Fudef - relatório MEC". In: DOURADO, L. F. Financiamento da educação básica. Campinas: Autores Associados; Goiana: Editora da UFG, 1999.

BRASIL. Lei $n^{\circ}$ 5.692, de 11 de agosto de 1971. Fixa diretrizes e bases para o ensino de $1^{\circ}$ e $2^{\circ}$ graus. Brasília, 1971. Disponível em: <http://www.planalto.gov.br/ccivil_03/leis/L5692.htm>. Acesso em 20/11/2010

. Lei $n^{\circ}$ 4.024/61, 20 de dezembro de 1961. Fixa as

Diretrizes e Bases da Educação Nacional. Brasília, 1961. Disponível em: <http:/ /www6.senado.gov.br/legislacao/ ListaPublicacoes.action?id=102346>. Acesso em: 20 nov. 2010.

. Constituição (1988). Constituição da República Federativa do Brasil: promulgada em 5 de outubro de 1988. Brasília, 1988. Disponível em: <http:/ / www.planalto. gov.br/ccivil_03/constituicao/constitui\%C3\%A7ao.htm>. Acesso em: 20 nov. 2010.

. Constituição (1891). Constituição da República dos Estados Unidos do Brasil, de 24 de fevereiro de 1891).Disponível em: <http://www.planalto.gov.br/ccivil_03/constituicao/ Constituicao91.htm> Acesso em: 20 nov. 2010.

. Constituição (1934). Constituição da República dos Estados Unidos do Brasil, de 16 de julho de 1934 . Disponível em: <http://www.planalto.gov.br/ccivil_03/constituicao/ constitui\%C3\%A7ao34.htm> Acesso em: 20 nov. 2010.

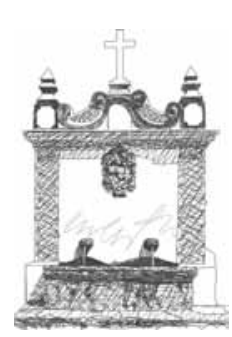

161 
BRASIL. Constituição (1946). Constituição dos Estados Unidos do Brasil, de 18 de setembro de 1946. Disponível em: <http://www.planalto.gov.br/ccivil/Constituicao/ Constitui\%C3\%A7ao46.htm>. Acesso em: 20 nov. 2010.

Decreto-Lei n. 8.530, de 2 de janeiro de 1946. Lei Orgânica do Ensino Normal. Disponível em: <http:/ / www.soleis.adv.br/ leiorganicaensinonormal.htm> Acesso em: 27 out. 2010.

Decreto-Lei n. 8.529, de 2 de janeiro de 1946. Lei Orgânica do Ensino Primário. Disponível em: <http:/ /www.soleis.adv.br/ leiorganicaensinoprimario.htm>. Acesso em: 27 out. 2010.

. Constituição (1967). Constituição da República Federativa do Brasil, de 24 de janeiro de 1967. Disponível em: <http://www.planalto.gov.br/ccivil_03/constituicao/ Constitui\%C3\%A7ao67.htm>. Acesso em: 27 out. 2010.

. Lei n. 9.394, de 20 de dezembro de 1996. Estabelece as diretrizes e bases da educação nacional. Brasília, 1996. Disponível em: <http:/ / portal.mec.gov.br/seed/arquivos/ pdf/tvescola/leis/lein9394.pdf>. Acesso em: 30 nov. 2010..

. Lei n. 9.424, de 24 de dezembro de 1996. Dispõe sobre o Fundo de Manutenção e Desenvolvimento do Ensino Fundamental e Valorização do Magistério, na forma prevista no art. $60, \S 7^{\circ}$ do Ato das Disposições Constitucionais Transitórias e dá outras providências. Brasília, 1996. Disponível em: <http://www.planalto.gov.br/ccivil_03/leis/L9424.htm>. Acesso em: 30 nov. 2010..

Resolução CNE/CEB n. 3, de 8 de outubro de 1997. Fixa Diretrizes para os Novos Planos de Carreira e de Remuneração para o Magistério dos Estados, do Distrito Federal e dos 162 Municípios. Brasília, 1997. 
BRASIL. Parecer do CNE n. 10, de 3 de setembro de 1997.

Estabelece as Diretrizes para os Novos Planos de Carreira e de Remuneração do Magistério dos Estados, do Distrito Federal e dos Municípios. Brasília, 1997.

. Emenda Constitucional n. 14, de 1996. Modifica os artigos 34, 208, 211 e 212 da Constituição Federal e dá nova redação ao artigo 60 do Ato das Disposições Constitucionais Transitórias. Disponível em: <http:/ / portal.mec.gov.br/arquivos/pdf/ e1496.pdf>. Acesso em: 30 nov. 2010..

. Emenda Constitucional n. 19, de 1998. Modifica o regime e dispõe sobre princípios e normas da Administração Pública, servidores e agentes políticos, controle de despesas e finanças públicas e custeio de atividades a cargo do Distrito Federal, e dá outras providências. Disponível em: <http://www.planalto. gov.br/ccivil_03/constituicao/emendas/emc/emc19.htm>. Acesso em: 30 nov. 2010.

. Lei n. 11.494, de 20 de junho de 2007. Regulamenta o Fundo de Manutenção e Desenvolvimento da Educação Básica e de Valorização dos Profissionais da Educação - FUNDEB, de que trata o art. 60 do Ato das Disposições Constitucionais Transitórias; altera a Lei no 10.195, de 14 de fevereiro de 2001; revoga dispositivos das Leis nos 9.424, de 24 de dezembro de 1996, 10.880, de 9 de junho de 2004, e 10.845, de 5 de março de2004, e dá outras providências. Brasília, 2007. Disponível em: <http://www.planalto.gov.br/ccivil_03/_ato2007-2010/2007/ Lei/L11494.htm>. Acesso em: 07 dez. 2010..

. Lei n. 11.738, de 16 de julho de 2008. Regulamenta a alínea " $\mathrm{e}$ " do inciso III do caput do art. 60 do Ato das Disposições Constitucionais Transitórias, para instituir o piso salarial profissional nacional para os profissionais do magistério

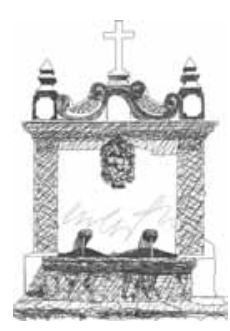


público da educação básica. Brasília, 2008. Disponível em: <http://www.planalto.gov.br/ccivil_03/_ato2007-2010/2008/ lei/111738.htm>. Acesso em: 07 dez. 2010..

BRASIL. Parecer CNE/CEB n. 9/2009, aprovado em 2 de abril de 2009. Revisão da Resolução CNE/CEB n. 3/97, que fixa Diretrizes para os novos Planos de Carreira e de Remuneração para o Magistério dos Estados, do Distrito Federal e dos Municípios. Brasília, 2009. Disponível em: <http:/ / portal.mec.gov.br/ index.php?option=com_content\&view=article\&id=12745:ceb2009\&catid=323:orgaos-vinculados>. Acesso em: 07 dez. 2010.

. Resolução do CNE/CEB n. 2, de 28 de maio de 2009. Fixa as Diretrizes Nacionais para os Planos de Carreira e Remuneração dos Profissionais do Magistério da Educação Básica Pública, em conformidade com o artigo $6^{\circ}$ da Lei n. 11.738, de 16 de julho de 2008, e com base nos artigos 206 e 211 da Constituição Federal, nos artigos $8^{\circ}$, § $1^{\circ}$, e 67 da Lei n. 9.394, de 20 de dezembro de 1996, e no artigo 40 da Lei n. 11.494, de 20 de junho de 2007.

. Decreto-Lei Imperial, de 15 de outubro de 1827.

Disponível em: <http://www.adur-rj.org.br/5com/pop-up/ decreto-lei_imperial.htm>. Aceso em: 20 out. 2010.

. Lei n. 10.172, de 9 de janeiro de 2001. Plano Nacional de Educação (PNE). Brasília: MEC, 2006. Disponível em: <www.mec.gov.br>. Acesso em: 18 jun. 2006.

. Parecer CNE/CEB n. 2, de 26 de fevereiro de 1997. Diretrizes para a Carreira e Remuneração do Magistério Público.

. Emenda Constitucional n. 53, de 19 de dezembro de 2006. Dá nova redação aos arts. 7º 23, 30, 206, 208, 211 e 121 da Constituição Federal e ao art. 60 do Ato das Disposições 
Constitucionais Transitórias. Brasília, 2006. Disponível em: <http://www.planalto.gov.br/ccivil_03/constituicao/ emendas/emc/emc53.htm>. Acesso em: 07 dez. 2010.

DAVIES, N. Verbas da Educação: o legal x o real. Niterói, RJ: EdUFF, 2000.

FURTER, P. Os sistemas de formação em seus contextos: introdução a um método de educação comparada. Rio de Janeiro: FGV/ IESAE, 1980.

MARTINS, V. Como surgiu o Dia do Professor. In: Arte educação-Querido Mestre. Disponível em <http:/ / www. arteducacao.pro.br/homenagem/queridomestre.htm>. Acesso em: 20 out. 2010.

MELCHIOR, J. C. de A. O financiamento da educação no Brasil. São Paulo: EPU, 1987.

OIT/UNESCO. 1966. A recomendação da OIT/UNESCO de 1966 relativa ao Estatuto dos Professores e Recomendação de 1997 da UNESCO relativa ao Estatuto do Pessoal do Ensino Superior. Paris, 5 de outubro de 1966. Disponível em: <http:/ / unesdoc.unesco.org/ images/0016/001604/160495por.pdf>. Acesso em: 20 out. 2010.

OLIVEIRA, R. P. de. O financiamento da educação. In: OLIVEIRA, R. P. de; ADRIÃO, T. Gestão, financiamento e direito à educação: análise da Constituição Federal e da LDB. 3. ed. São Paulo: Xamã, 2007.

PINTO, J. M. R. Os recursos para a educação no Brasil no contexto das finanças públicas. Brasília: Editora Plano, 2000.

UNESCO, 2000. O Marco de Ação de Dakar - Educação Para Todos:

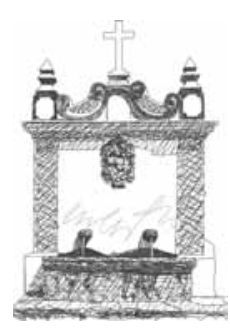


Atingindo nossos Compromissos Coletivos. Cúpula Mundial de Educação - Dakar, Senegal - 2000.

Disponível em: <http://www.oei.es/quipu/marco_dakar_ portugues.pdf $>$. Acesso em: 20 out. 2010.

UNESCO, 1998. Declaração Mundial de Educação Para Todos - satisfação das necessidades básicas de aprendizagem. Jomtien, 1990. Disponível em: <http:/ / unesdoc.unesco.org/ images/0008/000862/086291 por.pdf>. Acesso em: 20 out. 2010. 


\title{
Career and salary of teachers in Basic Education: some legal boundaries
}

\begin{abstract}
This paper presents aspects of the career and of the salary of Basic Education teachers in some international documents and in the Brazilian legislation. It was possible to notice that legal orientations are present in our society since a long time, which reveals the importance of teachers in providing a quality education. However, it was not possible to identify any continuity on the Brazilian legal proposals, but only contradictory movements in relation to the assurance and advancement of rights, as well as to the development of career and decent wages to teachers. In Brazil, it was in democratic periods that there were greater legal concern about teacher's career and salary, such as the current constitutional linkage to finance education. From the last Federal Constitution (1988), it was possible to notice an increase in the number of legal provisions on teacher's career and salary, due to the duty of states and municipalities to develop career plans for educationprofessionals.
\end{abstract}

Keywords: Basic Education; teachers salary; teachers career.

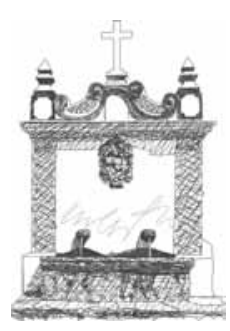

